\title{
The Problem of Social-Psychological Maladjustment of People in Today's Economic Conditions
}

\author{
Artamonova A.A. ${ }^{a}$ \\ Ajupov A.A. ${ }^{b}$ \\ a Samara State University, Samara, 443011, Russia \\ ${ }^{b}$ Kazan Federal University, Institute of Management, Economics and Finance, Kazan, 420008, Russia \\ Email: art_alla@bk.ru
}

\section{Doi:10.5901/mjss.2015.v6n1s3p24}

\begin{abstract}
The article comprises a set of theoretical and methodological bases of adaptation inclusion in a range of important psychological problems is defined as the real demands of life and logic of the development of scientific psychology. Special attention is paid to adaptation - maladjustment, because in this case the person is experiencing problems and the violation of their social activity. In relation to the rights applicable category of mental, psychological and social maladjustment. Social adaptation acquires exceptional importance in the critical periods of human activity, and in periods of radical economic and social reforms.
\end{abstract}

Keywords: social adaptation, maladjustment, a self-adaptive, self adjusting, images mature, social conditions of life, active adaptation, economic adaptation, socialization, economic and social reforms.

\section{Introduction}

Adaptation represents some of the very real ways to preserve vitality, not only in today's rapidly changing world, but also in the future. The inclusion of adaptation in a range of important psychological problems is defined as the real demands of life and logic of the development of scientific psychology. Modern psychological science, and actively involved in largescale solution relevant to society's problems, faced with the need to understand the changes in human psychology. The searches for explanations of behavioral modifications, the definition of the integral factors organize psychological transformations associated with the study of adaptation.

Special attention is paid to adaptation - maladjustment, because in this case the person is experiencing problems and the violation of their social activity. The analysis of theoretical and methodological approaches in various scientific fields, including philosophy, biology, medicine, valeology, sociology, pedagogy, allowed us to identify several generalized semantic aspects of adaptation and disadaptation: a review of life in the changing conditions of existence (R.M. Baevsky, I.G. Bezpalko, N.N. Wasilewski, N.R. Derapa, N.I. Kosenkov, V.N. Krutko, F.H. Meyerson, V.P. Petlenko, S.I. Soroko); adaptation as adaptation to the changed environment (V.A. Ananiev, E.V. Vitenberg, A.I. Volozhin, I.B. Germanova, R.G lluchanok, V.P. Kaznacheev, L.A. Korostyleva, A.G. Maklakov, I.A. Miloslavov, N.N. Obozov, A.N. Severtsev, Y.K. Subbotin); achieving sustainability in a modified environment (F.B. Berezin, L.F. Burlachuck, E.Y. Korzhova, V.I. Medvedev, V.A. Petrovsky). Changes in the social, cultural, objective and natural environment, put experts need to study exclusion from the position of man as the subject of life, as a holistic personality, consciously choose the direction and how to build your own path of life in an unstable world.

\section{Theory}

The biggest problem in solving these issues arises with those social layers that are due to objective and subjective factors. To one of these groups include young people. Their social and psychological vulnerability, the vulnerability does not allow the individual to solve problems in modern society problems. The elderly, acquiring the status of a pensioner will lose not only the production of communication, but also a significant part of other public functions. It is obvious that older people in contemporary Russian society became one of the most vulnerable socio-demographic groups [1].

Exclusion represents any violation of adaptation, the adaptation of the organism to ever-changing external or 
internal environment. The degree of maladjustment characterized by the level of disorganization of the functional systems of the body.

In relation to the rights applicable category of mental, psychological and social maladjustment. Objective manifestations of maladjustment are expressed in a certain type of behavior, and subjective - a wide range of emotional shifts. Personal maladjustment may lead to the formation of suicidal behavior in case of inability to implement the basic values. Exclusion from the social environment is not a simple lack of fitness to others, and the complex sociopsychological condition. Rejection by a group of individual, social and psychological isolation and the associated psychological state of frustrirovannosti and depression, inadequate communication skills and behavioral disorganization, internal stiffness and underlined shyness - this is not an exhaustive list of symptoms [2].

\section{Results}

Getadaptercount - state due to certain reasons. It can act as some object of desire on the part of the individual: the individual may actively seek to evade a group of institutions that do not accept the views of others and to resist them, to complicate relations with others and to exacerbate conflicts. In one case, getadaptercount individual may come from the social group, "rejecting" him, and from the inability of the individual to fit into their environment, and the other from the desire of the person for violation of state socio-psychological balance in relationships and overcome the requirements of opportunism. You can select specific variations of social and intrapersonal interaction in the framework of the «adaptation-exclusion»:

1. Maladjustment to society - a self-adaptive. This particular pattern of social and intrapersonal interaction may, for example, be expressed in those cases when the person increases self-esteem and internal consistency as how it deviance behaves in relation to group institutions, isolated from others, and, in General, does not fit into the whole "body" of the troupe.

2. Adaptation to society - images mature. This pattern is inversive previous option. As an example you can refer to the psychological state of the internal disagreement and dissatisfaction with himself, arose and increasing in if conformal own behavior and compromise to the environment is "forced landing".

3. Maladjustment to society - self adjusting. This time understands the pattern of interaction, which indicates the transition of interpersonal intrapersonal conflicts in the plan. Misalignment with the outside world is interconnected with interpersonally mismatch. Psycho work in such cases is very complex and includes two complementary strategies: regulation of relations of the individual with others through the stimulation of her "work" self-regulation and, on the contrary, the achievement of the required level of internal consistency through the settlement of its social relations.

4. Adaptation to society - maladjustment to society. Aspiration adaptation to society can lead to the opposite result where the means of achieving this goal are maladaptive in nature.

5. Self adjusting - images mature. The selection of this pattern may seem speculative. However, if reflected upon its contents, then you can at least point to one fact: the reason semi adaptive activity of a person can be a sense of inner coherence. Images mature as the cause (or condition) in this case precedes and determines the complex intrapersonal processes aimed at acceptance of itself and the achievement of the required level of intra-psychic coherence [3].

Social adaptation is not only a state but a process, during which the social organism acquires balance and resistance to impact and influence of the social environment.

Social adaptation acquires exceptional importance in the critical periods of human activity, and in periods of radical economic and social reforms.

Currently, greater attention to the development of this problem is determined by the needs of practical problems associated with accelerating the process of human adaptation to the new conditions in different spheres of life: professional, social, political, legal, etc. Influence the inclusion of a person in a new social environment to optimize this controversial process, is possible only in the case, if known, its nature, structure and mechanisms, as well as the specificity of its occurrence in various areas of social life [4].

In modern scientific literature problems of adaptation are considered in several areas: biological, medical, pedagogical, psychological, sociological, cyber.

Under the social adaptation refers to the process of active adaptation of man to the new social conditions of life. In the process of adaptation of the person is the subject of the impact of the social environment and the active subject, aware of the impact of this environment. The process of adaptation is a broad polyphony learning of social values through the mechanisms of socialization. Man as an active subject develops and uses in its life the products of human civilization, 
which include managerial, economic, psychological, educational technology and methods development of social space. In fact, all elements of human culture are involved in the formation of personality through the adaptation mechanism, which is an integral a necessary part of the dominant social development. Sociality is an essential aspect of a human being, its qualitative characteristics. All kinds of adaptation are interrelated, but the dominant is social. Full social adaptation of the person includes physiological, managerial, economic, pedagogical, psychological and professional adaptation.

Managerial (organizational) adaptation. Mesopotamia (at work, at home), to create preconditions for the development of its social role, to influence, to provide activities that meet the interests of society and the individual [5].

Social adaptation is a process that is manageable. Management can be carried out not only in line with the impact of social institutions on the person in the course of its production, non-production, before-production, post-production activity, but also in the mainstream of government. The latter implies demanding, self-critical attitude of man to himself, to his thoughts and actions.

Economic adaptation. This is a very complex process of learning new socio-economic norms and principles of economic relations between individuals, entities. For the technology of social work is important here is the so-called "social unit", including adapting to the actual social reality of the size of unemployment benefits, wages, pensions and benefits. They must meet not only the physical, but also social and cultural needs of the person. It is impossible to speak about a full-fledged social adaptation of the person, if he is poor or doesn't population drags out a miserable existence, or is unemployed.

Pedagogical adaptation. This adaptation to the education system, training and education, which form a system of value orientations of the individual. It should also be pointed out that the adaptation of the person depends on a comprehensive exposure to the natural, genetic, geographical factors, though the latter do not play a decisive role in his socialization.

Adaptive changes are more or less conscious of the changes through which the identity transformation, changes the situation. Changes always accompany human life, therefore, for each individual it is important to be prepared for critical periods, turning moments, conscious revision of their position in life in the new circumstances. This creates real conditions of readiness to lead full and active adaptation.

Psychological adaptation. In psychology, adaptation is considered as a process of adaptation of the senses to the peculiarities of acting on them incentives for their understanding and protection of receptors from excessive load. The psychological process of adaptation occurs continuously, because the constantly changing socio-economic conditions, political and ethical orientation, environmental conditions, etc.

Professional adaptation is the adaptation of the individual to a new kind of professional activity; the new social environment, working conditions and peculiarities of a particular specialty. The professional success of adaptation depends on the propensity of adaptate to a specific professional activity, the coincidence of public and personal motivation and other reasons.

Adaptation encompasses a broad range of concepts from elementary experience of adaptation of organism to environment, to complex socio-psychological adaptation of personality in the process of socialization. Man as a subject of activity should be considered as a complex, multidimensional socio-psychological-biophysiological system. As part of the system approach, the adaptation is presented and the process and the result of the operation of the integral selfregulating system, adaptability which is provided by the interaction of its individual elements.

Therefore, a complete study of human adaptation is only possible with the implementation of a comprehensive approach to the study of all organization levels: from the psychosocial to the biological with regard to their relationship and interaction [6].

Social adaptation as a mechanism of socialization.

Social adaptation is an integrative indicator of the human condition, reflecting its ability to perform certain biosocial functions, namely:

- $\quad$ an adequate perception of the environment and its own body;

- an adequate system of relationships and communication with others; ability to work, study, leisure and recreation;

- a variability (adaptability) behavior in accordance with the role expectations of others.

In the study of adaptation one of the most urgent issues is the question of the relationship between adaptation and socialization. The processes of socialization and social adaptation are closely interrelated, as they reflect a single process of interaction between the individual and society. Often socialization is associated only with the General development and adaptation - adaptive processes already established personality in the new conditions of communication and activity. The phenomenon of socialization is defined as the process and the result of active play of the individual's social experience, ongoing communication and activities. The concept of socialization largely has to do with social experience, development 
and formation of personality under the influence of society, institutions and agents of socialization. In the process of socialization formed the psychological mechanisms of interaction of the individual with the environment, carried out in the process of adaptation.

Socialization is the process of identity formation in certain social conditions, the absorption of human social experience in which man transforms social experience in their own values and orientation, selectively enters into your system behavior to the norms and patterns of behavior that are accepted in society or group. Standards of conduct, morality, human beliefs are defined by the norms that are accepted in this society. In the process of socialization of the person internalizes social norms, masters the ways of fulfilling social roles, skills, social behavior. Socialization is based on the knowledge of the identity of social reality.

The result of the socialization of the individual is evident in his personality, perceived them and society as socially valuable qualities - qualities of mind, character, manners and behavior, manners and education, social adaptability of the individual.

The main forms of social adaptation of the individual education and training. However, socialization is not limited to the education and upbringing. In the process of socialization is formed attitude personality - principles of behavior based on stable views of personality in its place and role in the life of society. This position is formed by a complex of social factors.

Thus, socialization is a process, and the result of the assignment (internalization) of the individual systems of social values and socio adapted behavior, carried out both in terms of purposeful influence of social institutions and the natural influence on the personality of the different life circumstances.

Thus, in the course of socialization of the person acts as the object, perceiving, receiving, and acquiring traditions, norms, roles created by society; socialization ensures the normal functioning of the individual in society [7]. In the course of socialization are the development, formation and development of personality, at the same time, the socialization is a prerequisite for the adaptation of the individual in society. Social adaptation is one of the main mechanisms of socialization, one of the ways more complete socialization.

Social adaptation is:

a) an ongoing process of active adaptation of the individual to the new social environment;

b) the result of this process.

Socio-psychological context of social adaptation is the convergence of the goals and values of the group and its individual assimilation of norms, traditions, group culture, and participation in role-playing group structure.

In the course of social adaptation is not only the adaptation of the individual to the new social conditions, but also the realization of his needs, interests and aspirations; the identity is included in a new social environment, it becomes a full member, asserting itself and develop their individuality. As a result of social adaptation are formed social quality of communication, behavior and action in society, due to which the person realizes their aspirations, needs, interests, and can define themselves.

O. I. Zotova and I. K. Kryazheva emphasize the activity of the individual in the process of social adaptation. They consider the socio-psychological adaptation as the interaction of the individual and the social environment, which leads to the right outcome goals and values of individuals and groups. Adaptation occurs when the social environment contributes to the realization of the needs and aspirations of the individual, is discovering and developing her personality.

In the description of the adaptation process are concepts such as "overcoming", "focus", "personality development", "assertion".

Depending on the structure of needs and motives of personality are formed following types of adaptation process:

- $\quad$ the type, characterized by the predominance of active influence on the social environment;

- the type that is determined by a passive, conformal adoption of goals and value orientations of the group.

As noted by A.A. Rean, there is also a third type of adaptation process, which is the most common and the most effective from the point of view of adaptation. This probability is a combined type, based on the use of both the above types. When choosing a person evaluates the likelihood of successful adaptation for different types of adaptive strategies [8]. At the same time evaluated: a) the requirements of the social environment - their strength, the degree of restriction of the goals of the individual, the degree destabilizing effect and so on; b) the potential of the individual in terms of changes, adaptations of the environment to itself.

The majority of domestic psychologists distinguish two levels of adaptation personality: full adaptation and disadaptation.

A.N. Zhmirikov proposes to consider the following criteria of adaptability:

- the degree of integration of the personality with the macro - and microenvironment;

- the degree of realization of personal potential; 
- the emotional health.

A.A. Rean associates building a model of social adaptation to the criteria of internal and external plan. The internal criterion involves emotional stability, personal conformity, satisfaction, absence of distress, feelings of threat and state of emotional tension. External criterion reflects the actual behavior of the individual units of society, the requirements of the environment, the rules accepted in society, and the criteria of normative behavior. Thus, maladjustment external criterion can occur simultaneously with adaptation on internal criteria. The system of social adaptation is the adaptation of both external and internal criteria [9].

\section{Conclusions}

Thus, social adaptation implies ways of adaptation, regulation, harmonization of the interaction of the individual with the environment. In the process of social adaptation of the person acts as an active subject, which adapts to the environment in accordance with their needs, interests, and aspirations and actively identifies?

The main component and mechanism of the process of socialization is adapted, under the influence of which a man acquires features of sociality becomes a full member of society. However, to become a social being, not having domestic premises under the influence of some external conditions [10]. Yes, and the degree of sociality adult is far from complete merger with the society, otherwise there would be no problems of maladjustment, adjustment problems of antisocial behavior, people would not live in the world, does not suffer from the fact that it does not understand others. If the notion of socio-psychological adaptation reflects the phenomenon of inclusion of interaction and integration with the community and self-determination and social-psychological adjustment of the individual is an optimal implementation of the internal capabilities of the person and his personal potential in social activities, ability, keeping herself as a person, to interact with the surrounding society in a particular living conditions, the social-psychological maladjustment is considered by most authors as a process violations homeostatic balance of personality and environment, as a violation of adaptation of the individual in virtue of those or other reasons; as a violation of due to the "mismatch innate personal needs limiting demand social environment"; as the inability of the individual to adapt to their own needs and aspirations.

We believe that overcoming social exclusion and the formation of an independent lifestyle of modern people largely depends on the participation of different specialists (doctors, psychologists, teachers, speech therapists, social workers, specialists in culture, specialists in the rehabilitation of persons with disabilities and others) [11]. This process requires the interaction of scientists and practitioners, governmental and non-governmental institutions, the General public, the media. The objectives of technologies used included the neutralization and elimination of the causes of exclusion in the sociocultural sphere; initiation and development of professional social and cultural activities, providing them with concrete assistance in accordance with their capabilities and interests; support for human rights in the area of leisure with regard to ethnicity, age, religious and other factors.

As a diagnostic tool we used $16 \mathrm{pF}$ - questionnaire of Kettell. Currently, various forms of $16 \mathrm{PF}$ - questionnaire are the most popular means of rapid diagnosis of a personality. They are used in all situations that require knowledge of individual psychological characteristics of the person. The questionnaire diagnoses of personality traits that R. B. of Cattell calls constitutional factors. These factors are: factor And "isolation - sociability"; factor In "intelligence"; the factor "emotional instability - emotional stability"; the factor E "subordination - dominance"; the factor F "restraint - expression; factor G "exposure feelings - a high standard of conduct; factor H "shyness - boldness"; factor I "stiffness - sensitivity; the factor L "trust - suspicion"; factor M practicality - developed imagination"; the factor N "straightness - diplomacy"; the factor Of "confidence in itself - anxiety"; the factor Q1 "conservatism - radicalism"; factor Q2 "conformity - nonconformity"; factor Q3 "low self-control - high self-control"; the factor Q4 "relaxation - tension"; factor MD "adequacy of self-esteem".

The Test of Rosenzweig - experimental-psychological research methodology a frustrated reaction was first described in 1944. Rosenzweig and called the "Method of drawing frustrations". Stimulating situation of this method is a schematic contour drawing, which depicts two persons or more engaged haven't finished talking. Characters depicted may vary by sex, age and other characteristics. Total for all figures is the presence of a character in a frustrated situation. The technique consists of 24 images, which depict people in a frustrated situation. The situation depicted in the figures, can be divided into two main groups.

1. Situation "obstacles". In these cases an obstacle, the character or subject is daunting, confusing word or some other way.

2. Situation "accusations". The subject is the object of accusations.

Among these types there is a connection, because the situation "accusations" implies that it was preceded by the situation "obstacles", where frustrator was in turn frostreaver. Sometimes a person can interpret the situation "accusations" as a situation of "obstacles", or vice versa. 
In the field of diagnostics protective mechanisms primary role was originally given projective research methods. The most serious study of the measurements were carried out using the technique of Rorschach. However, given that using projective techniques cannot systematized to assess the full range of protective mechanisms, a number of researchers attempted to create questionnaires that measure protective mechanisms are based on either self-report test, or taking into account the opinion of the interviewer (expert evaluation). From more than a dozen existing methods, all but a few, limited to measuring only the individual methods are sewn. Most often this "denial", "rationalization", "projection". Some questionnaires, just rebuilt from claims MMPI. The problem of diagnostics of psychological defense mechanisms is complicated by the fact that the authors of the methods have different theoretical orientation that generates a large number of terminological inaccuracies and the problem of incomparability of data obtained by different authors.

Against this background, the LSI technique, described in 1979 on the basis of psychoevolutionary theory R. Pluchek and structural theories of personality, of Kellerman, admittedly the most successful diagnostic tool to diagnose the whole system of MPZ. To identify as leading, basic mechanisms, and to assess the degree of tension of each mechanism PZ.

The undeniable advantages of this technique are its theoretical validity and discriminant validity, targeted, multidimensionality and structural simplicity. As a strategic factor examines the relationship of individual species PZ with different effective States and diagnostic concepts.

The study of the level of social adaptation in a group of freshmen, which showed that the average level of social adaptation is equal to $\approx 50 \%$.

Investigated individually-psychological features of students ' first year of University, which showed that:

first, extra peritoneal personality is not an indicator of a more successful social adaptation to the social environment;

secondly, pronounced communicative personality traits are not an indicator of a more successful social adaptation;

third, what personality, which is characterized by high anxiety, dissatisfaction, lack of confidence, low stress less adapted to their social environment, i.e. anxiety occurs as a result of the interaction of personality and its environment;

fourth, a more successful adaptation to the social environment will contribute to significant emotional characteristics such as emotional stability, confidence in themselves and their abilities, calm adequate perception of reality;

fifthly, that the mechanism of suppression provides care from anxiety and accompanied by the emotion of fear.

In the study we can conclude that successful social adjustment of the individual depends on the severity of psychological characteristics, namely the emotional characteristics of the individual.

\section{References}

Antsiferova, L.I. Colpocytological studies in gerontological practice. // Klinicheskaia laboratornaia diagnostika. 2005.

Asmolov, A.G. Strategy and methodology for the sociocultural reform of education. // Psychology in Russia: State of the Art.

Asmolov, A.G. A historical evolutionary paradigm for designing a variety of worlds: Activity as existence. // Voprosy Psikhologii. 2008.

Asmolov, A.G.,Pasternak, N.A. Cognitive egocentricity as a mechanism of social behavior // Voprosy Psikhologii. 2006.

Leontiev, D.A. Personal meaning: A challenge for psychology. // Journal of Positive Psychology. 2013.

Leontiev, D.A. The personality dimension of human development // Voprosy Psikhologii. 2013.

Leontiev, D.A. Personal meaning as the basis of motivational processes. // Motivation, Consciousness and Self-Regulation. 2012.

Rean, A.A. Acmeology of a personality. // Psikhologicheskii Zhurnal. 2000.

Rean, A.A. Problems and perspectives of the development of personality's locus of control conception. // Psikhologicheskii Zhurnal. 1998.

Fromm, E. The philosophy basic to freud's psychoanalysis. // Pastoral Psychology. 1962.

Murphy, D.,Frank, L.K.,Mowrer, O.H.,Fromm, E. Frustration and life. // Pastoral Psychology. 1952.

Yartiev A.F., Tufetulov A.M. Effect of license holder's cost-flow on long-term development of oil industry // Mediterranean Journal of Social Sciences vol. 5 № 24, November 2014, pp. 417-420

Valitov, S.M.,Sirazetdinova, A.Z. (2014). Project risks' management model on an industrial entreprise. Asian Social Science, 10 (21), pp. 242-249 